\title{
The International Reference Ionosphere 2012 - a model of international collaboration ${ }^{\text {th }}$
}

\author{
Dieter Bilitza ${ }^{1,2, *}$, David Altadill ${ }^{3}$, Yongliang Zhang ${ }^{4}$, Chris Mertens $^{5}$, Vladimir Truhlik ${ }^{6}$, Phil Richards ${ }^{1}$, \\ Lee-Anne McKinnell ${ }^{7}$, and Bodo Reinisch ${ }^{8}$ \\ 1 George Mason University, School of Physics Astronomy and Computational Science, 4400 University Drive, Fairfax, Virginia, \\ USA \\ ${ }^{*}$ Corresponding author: dbilitza@gmu.edu \\ 2 NASA Goddard Space Flight Center, Heliospheric Physics Laboratory, Greenbelt, Maryland, USA \\ 3 Observatori de l'Ebre, CSIC, Uni. Ramon Llull, Roquetes, Spain \\ 4 The Johns Hopkins University Applied Physics Laboratory, 11100 Johns Hopkins Road, Laurel, MD 20723, USA \\ 5 NASA Langley Research Center, Science Directorate, Mail Stop 401B, Hampton, VA 23681-2199, USA \\ 6 Institute of Atmospheric Physics, ASCR, Prague 14131, Czech Republic \\ 7 SANSA Space Science, PO Box 32, Hermanus 7200, South Africa \\ 8 Center for Atmospheric Research, University of Massachusetts, Lowell, MA, USA
}

Received 5 October 2013 / Accepted 15 January 2014

\begin{abstract}
The International Reference Ionosphere (IRI) project was established jointly by the Committee on Space Research (COSPAR) and the International Union of Radio Science (URSI) in the late sixties with the goal to develop an international standard for the specification of plasma parameters in the Earth's ionosphere. COSPAR needed such a specification for the evaluation of environmental effects on spacecraft and experiments in space, and URSI for radiowave propagation studies and applications. At the request of COSPAR and URSI, IRI was developed as a data-based model to avoid the uncertainty of theory-based models which are only as good as the evolving theoretical understanding. Being based on most of the available and reliable observations of the ionospheric plasma from the ground and from space, IRI describes monthly averages of electron density, electron temperature, ion temperature, ion composition, and several additional parameters in the altitude range from $60 \mathrm{~km}$ to $2000 \mathrm{~km}$. A working group of about 50 international ionospheric experts is in charge of developing and improving the IRI model. Over time as new data became available and new modeling techniques emerged, steadily improved editions of the IRI model have been published. This paper gives a brief history of the IRI project and describes the latest version of the model, IRI-2012. It also briefly discusses efforts to develop a real-time IRI model. The IRI homepage is at http://IRImodel.org.
\end{abstract}

\section{Introduction}

The successful launch and operation of satellites in space, starting in the late fifties, gave us an in situ view of space conditions and initiated a technological revolution that is still ongoing. It brought us every-day conveniences like satellite-TV and the Global Positioning System (GPS) related services and a unique vantage point for looking at our blue planet for a better understanding of its weather and climate. From early on there was a need to better understand and model the environment in which these satellites were flying. These predictions are required during the planning phase, to evaluate environmental effects on spacecraft and experiment, and to develop an optimal mission and instrument design. This became painfully clear with early miscalculations of the solar cycle variations of neutral densities. Underestimating the large densities reached during solar maximum led to early de-orbiting of spacecraft most prominently of the Skylab space station. In the mid-1960s it became clear that international standard models were needed for the upper atmosphere (thermosphere) and the ionosphere. The international body charged with this task was the newly established Committee on Space Research (COSPAR), a union of the space agencies of all space-faring nations. First order of business was the

\footnotetext{
Dedicated to Karl Rawer, the father of IRI, on the occasion of his 100th birthday.
}

development of a model for the upper atmosphere to get a better estimate of the expected lifetime of satellites in space. The COSPAR International Reference Atmosphere (CIRA) working group was established and issued steadily improved models starting with CIRA-1961 (CIRA 1961). As requested by COSPAR this was an empirical model based on all available ground and space observations, and avoiding as much as possible dependence on the still evolving theoretical understanding of the thermosphere. Following the success and great benefit of the CIRA project, COSPAR initiated a similar endeavor for the ionosphere establishing the International Reference Ionosphere (IRI) project in 1968. Shortly thereafter the International Union of Radio Science (URSI) became a co-sponsor of the IRI project. With COSPAR and URSI the IRI project had the backing from the major international unions representing space-based ionospheric observations (COSPAR) and groundbased ionospheric observations (URSI). IRI development has benefitted greatly from the synergism between these two communities which are represented about evenly in the IRI Working Group and during annual IRI Workshops.

The goals and intent of the IRI project are summarized in its COSPAR/URSI Terms of Reference as follows:

The Task Group was established to develop and improve a standard model of the ionospheric plasma parameters. 


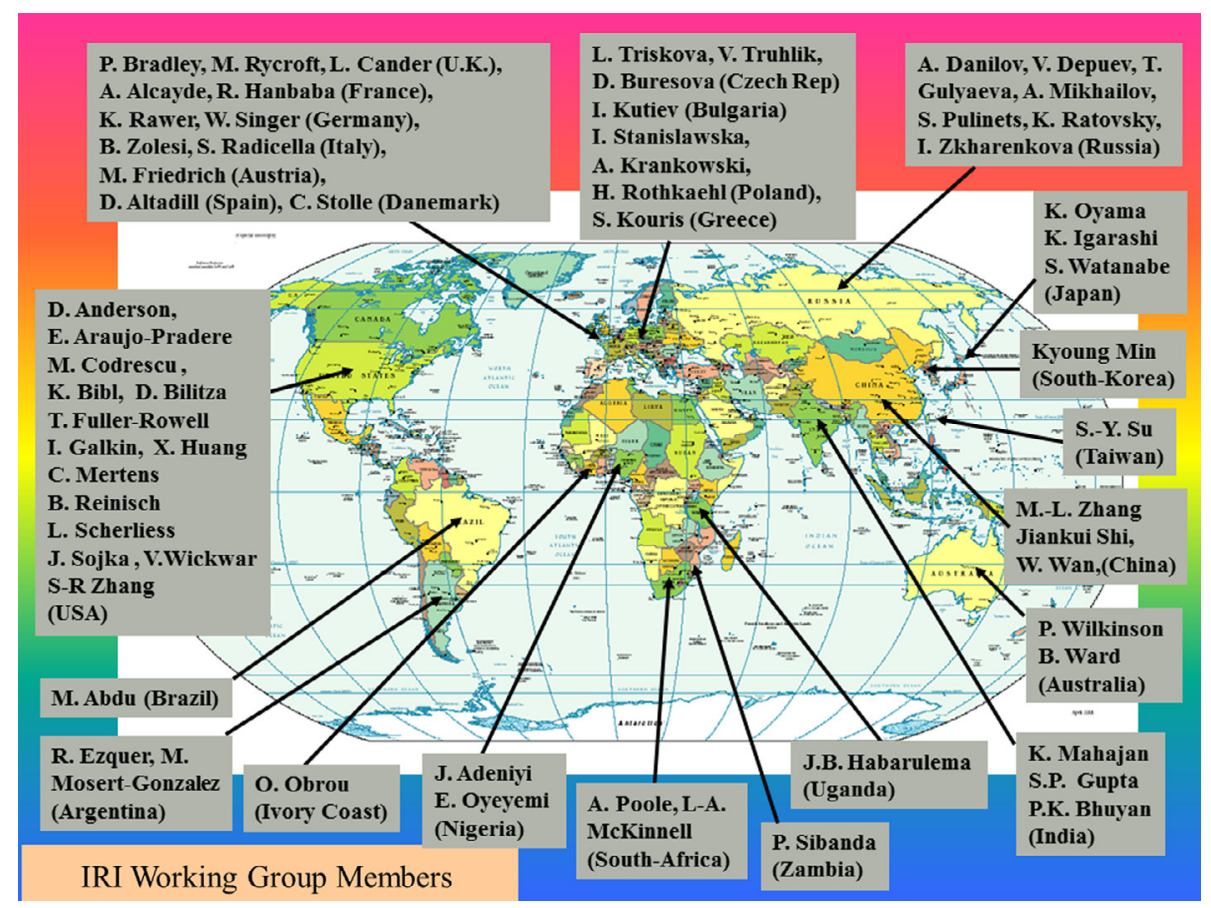

Fig. 1. Global distribution of members of the URSI/COSPAR Working Group for the International Reference Ionosphere.

The model should be primarily based on experimental evidence using all available ground and space data sources; theoretical considerations can be helpful in bridging data gaps and for internal consistency checks. Where discrepancies exist between different data sources, the IRI team should promote critical discussion to establish the reliability of the different databases. IRI should be updated as new data become available and as old data sources are fully evaluated and exploited. IRI is a joint working group of COSPAR and URSI. COSPAR's prime interest is in a general description of the ionosphere as part of the terrestrial environment for the evaluation of environmental effects on spacecraft and experiments in space. URSI's prime interest is in the electron density part of IRI for defining the background ionosphere for radiowave propagation studies and applications.

The IRI Working Group has grown over the years to a team of now 58 experts providing a balanced representation both in terms of global presence (see Fig. 1) as well as in covering the different ground and space techniques used to acquire ionospheric data. This good coverage technique-wise and globally has been a great asset for the IRI project because it helped gaining access to all essential ground and space data sets for the ionosphere. Other ingredients for the IRI success story include the annual IRI meetings where improvements and additions to the model are discussed and decided (http://irimodel.org/docs/iri_workshops.html), the publication of a selection of the papers from these workshops in dedicated issues of Advances in Space Research (http://irimodel.org/ docs/asr_list.html), and from early on open source availability of the IRI Fortran code, first on punched tape and cards, then on 9-track magnetic tape, then on floppy disk, then on CD, and finally a web interface for direct online computation. Important was also, of course, the continuous improvement process that resulted in the release of major new editions of the model about every 5 years. Some of the more important IRI milestones are listed in Table 1.

As an empirical model IRI has the advantage that it does not depend on the evolving theoretical understanding of the processes that shape the ionospheric plasma. A good example is the recently discovered four maxima structure in the longitudinal variation of F-peak electron density and of ionospheric electron content that was first observed with IMAGE/EUV observations (Immel et al. 2006), and then confirmed with data from CHAMP (Lühr et al. 2007) and TOPEX (Scherliess et al. 2008), and that is thought to be caused by nonmigrating, diurnal atmospheric tides that are driven by tropospheric weather in the tropics. While theoretical models still struggle to include this phenomenon in their modeling framework, inspection of the longitudinal variation of the F-peak density value $N m F 2$ in IRI revealed that IRI already reproduces this phenomenon (McNamara et al. 2010). The amplitude of these longitudinal variations is generally smaller in IRI than what is observed. But that is understandable, because IRI is based on monthly averages and the averaging process smoothes out some of the longitude structures.

A disadvantage of empirical models is the strong dependence on the underlying database. Regions and time periods not well covered by the database will result in diminished reliability of the model in these areas. So, for example, conditions during the most recent solar minimum in 2008/2009 were very different from earlier minima. The minimum was lower and more extended than earlier minima and as a result IRI, being built with the data from earlier minima, overestimated the plasma densities during the minimum period (Lühr \& Xiong 2010).

\section{Latest version of the model - IRI-2012}

The latest version of the IRI model, IRI-2012, includes several important improvements and new additions that will be 
Table 1. IRI milestones.

\begin{tabular}{|c|c|c|c|}
\hline Year & Event (reference) & Description & Database \\
\hline 1968 & $\begin{array}{l}\text { COSPAR establishes } \\
\text { IRI Working Group }\end{array}$ & \multicolumn{2}{|c|}{$\begin{array}{l}\text { K. Rawer, Chair; WG members predominantly from space } \\
\text { community (satellite and rocket measurements) }\end{array}$} \\
\hline 1969 & URSI joins IRI project & \multicolumn{2}{|c|}{ New WG members from ground observation community } \\
\hline 1975 & $\begin{array}{l}\text { IRI-75: Set of Tables } \\
\text { (Rawer et al. 1975) }\end{array}$ & $\begin{array}{l}\text { Representative values for equat., low, } \\
\text { mid latitudes }\end{array}$ & Ionosonde, ICS, AEROS \\
\hline 1978 & $\begin{array}{l}\text { IRI-79: URSI Special } \\
\text { Rep.: (Rawer et al. 1978a) }\end{array}$ & \multirow{2}{*}{$\begin{array}{l}\text { Global coverage using CCIR } \\
\text { maps for peak parameters, } \\
\text { modified for foF1 and foE; } \\
\text { using IG12 with foF2 }\end{array}$} & \multirow[t]{2}{*}{ Global ionosonde network } \\
\hline 1981 & $\begin{array}{l}\text { IRI-79: WDC-A-STP Rep. } \\
\text { (Rawer et al. 1981) }\end{array}$ & & \\
\hline 1986 & $\begin{array}{l}\text { IRI-86: floppy disk for PC } \\
\text { (Bilitza 1985, 1986) }\end{array}$ & $\begin{array}{l}\text { - Improved Ne at low latitudes } \\
\text { - Global Te, Ti models }\end{array}$ & $\begin{array}{l}\text { AEROS-A,-B, AE-C,-D,-E, ISIS-1, } \\
-2 \text {, ICS data }\end{array}$ \\
\hline 1990 & $\begin{array}{l}\text { IRI-90: NSSDC Report } \\
\text { (Bilitza 1990) }\end{array}$ & $\begin{array}{l}\text { - URSI maps for foF } 2 \\
\text { - Improved NmE model }\end{array}$ & $\begin{array}{l}\text { - More global ionosonde data } \\
\text { - Incoherent scatter (ICS) data }\end{array}$ \\
\hline 1995 & $\begin{array}{l}\text { IRI-95: online (IRIWeb) } \\
\text { (Bilitza 1997) }\end{array}$ & Improvements at low latitudes & DE-2 data \\
\hline 1999 & URSI resolution & \multicolumn{2}{|c|}{ IRI recognized as the international standard for the ionosphere } \\
\hline 2001 & IRI-2001 (Bilitza 2001) & $\begin{array}{l}\text { - Two new options for Ne D-region } \\
\text { - new models for } F_{1} \text { and } B_{0}, B_{1} \\
\text { - STORM model } \\
\text { - New model for Te }\end{array}$ & $\begin{array}{l}\text { - Rocket compilations } \\
\text { - Ionsonde network } \\
\text { - Stormtime ionosonde data } \\
\text { - Intercosmos } 19,24,25\end{array}$ \\
\hline 2007 & $\begin{array}{l}\text { IRI-2007 (Bilitza \& } \\
\text { Reinisch 2008) }\end{array}$ & $\begin{array}{l}\text { - Two new options for Ne topside } \\
\text { - new ion composition model } \\
\text { - spread-F occurrence model }\end{array}$ & $\begin{array}{l}\text { - TS: Alouette 1, 2, ISIS 1, } 2 \\
\text { - AE-C,-E, Intercosmos } 24 \\
\text { - Brazilian ionosonde data }\end{array}$ \\
\hline 2012 & IRI-2012 (this article) & See Section 2. & \\
\hline
\end{tabular}

explained in this section. These changes involve not only the representations of electron density, but also the description of electron temperature and ion composition. These improvements are the result of modeling efforts since the last major release, IRI-2007. Modeling progress is documented in several special issues of Advances in Space Research: Volume 39, Number 5, 2007; Volume 42, Number 4, August 2008; Volume 43, Number 11, June 2009; Volume 44, Number 6, September 2009; Volume 46, Number 8, October 2010; and two issues of Earth, Planets, and Space: Volume 63, Number 4, 2011 and Volume 64, Number 6, 2012.

\subsection{Electron density}

The ionospheric electron density profile reaches its highest density $N m F 2$ at the F2 peak height $h m F 2$. This point divides the electron density profile into its bottomside and topside parts. In IRI both profile parts are normalized to the F2 peak density and height. In the region below the F2 peak the profile structure is more complex because parts of the density profile are also normalized to the F1 or E peak. The buildup of the IRI electron density profile is illustrated in Figure 2 and is described in detail in the IRI-1990 report (Bilitza 1990). The region between the F2 and F1 heights is of special interest because of its effect on HF radio wave propagation and because of its non-negligible contribution to the ionospheric Total Electron Content (TEC). IRI-2012 includes a new model for this region that will be explained in the next section. With IRI-2012 the model will for the first time include a representation of the auroral oval boundaries and a description of storm effects in the auroral E region. These IRI additions will be explained in Sections 2.1.2 and 2.1.3, respectively.

\subsubsection{New models for $B_{0}$ and $B_{1}$}

The dependence of electron density $N_{e}$ on height $h$ in the region between the F2 and F1 heights is described in IRI by the function

$$
N_{e}(h)=N m F 2 \times \frac{\exp \left(-Z^{\mathrm{B}_{1}}\right)}{\cosh (Z)}, \quad Z=\frac{h m F 2-h}{B_{0}},
$$

with the bottomside thickness parameter $B_{0}$ and the shape parameter $B_{1}$. It is important to note that $B_{0}$ is different from the often used half-density thickness parameter $Y_{m}$ that is defined as $Y_{m}=h m F 2-h_{0.5}$ with the half-density height $h_{0.5}$ defined as $N\left(h_{0.5}\right)=0.5 \times N m F 2$. In our case the height $h x$, where $B_{0}=h m F 2-h x$ (or $Z=1$ ), is the height where the density profile has in fact dropped down to $0.24 \times N m F 2$. For the description of the global and temporal variations of the $B_{0}$ and $B_{1}$ parameters IRI offers two model options and is now adding a third one with IRI-2012 that is the recommended (default) option. All three models use as their database profiles obtained by ionosonde data analysis; they vary in the volume and global coverage of the data used and in the functions used to represent the variation patterns. Gulyaeva (1987) used mainly data from mid-latitude stations and her model consists of a functional description of the observed correlation between $h m F 2$ and $h_{0.5}$; using equation (1) this can then be converted into a model for $B_{0}$. A much wider range of conditions in terms of global, seasonal, and solar cycle conditions was covered by the $B_{0}$ model of Bilitza et al. (2000) that grew out of an IRI Task Force Activity held 


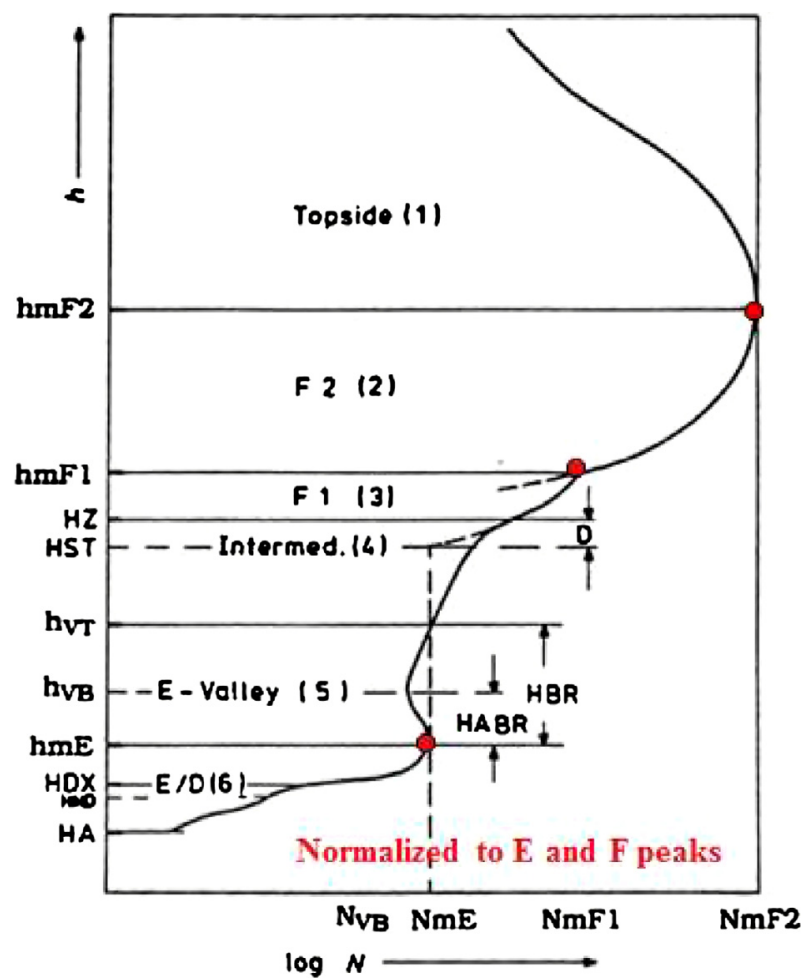

Fig. 2. Buildup of the IRI electron density profile and its separation into different regions.

at the International Centre of Theoretical Physics (ICTP) in Trieste, Italy. The model consists of a table of representative values and an interpolation scheme for intermediate conditions. It describes variations with Local Time (LT), season, solar activity (R-12), and modified magnetic latitude (modip). Bilitza et al. (2000) also provide a model for the shape parameter $B_{1}$ which shows a marked change from day to night. Epstein step-functions that vary from the daytime value of 1.9 to the nighttime value of 2.6 with smooth 1 -hr transitions at sunset and sunrise are used to model this behavior.

With improvements in ionosonde design and data analysis technique, the volume of bottomside profiles deduced from ionograms has been increasing steadily. Researchers have used this database to evaluate the two existing model options with the goal of determining which one provides the better results. It was found, however, that both model options have their shortcomings as was shown by Lee \& Reinisch (2006), Lee et al. (2008), Chen et al. (2006), Blanch et al. (2007), Zhang et al. (2008), and Sethi et al. (2009) with ionosonde data from a wide range of ground stations. Most importantly, marked discrepancies were found in the representation of seasonal and solar activity trends of $B_{0}$, with the Bilitza et al. (2000) model generally providing better results during daytime, while the Gulyaeva (1987) model performed better during nighttime. This was also confirmed by Lei et al. (2004) with Millstone Hill incoherent scatter data. Additionally, like the ionosonde comparisons they found that for $B_{1}$ diurnal variations are well represented by the Bilitza et al. (2000) model. But they also noted a $15 \%$ change in $B_{1}$ over a solar cycle that is currently not included in the IRI model. All these shortcomings are most likely due to the seasonal and solar cycle coverage limitations of the databases used to develop the earlier models. As a result of these studies the IRI team made it its highest priority to upgrade the $B_{0}$ and
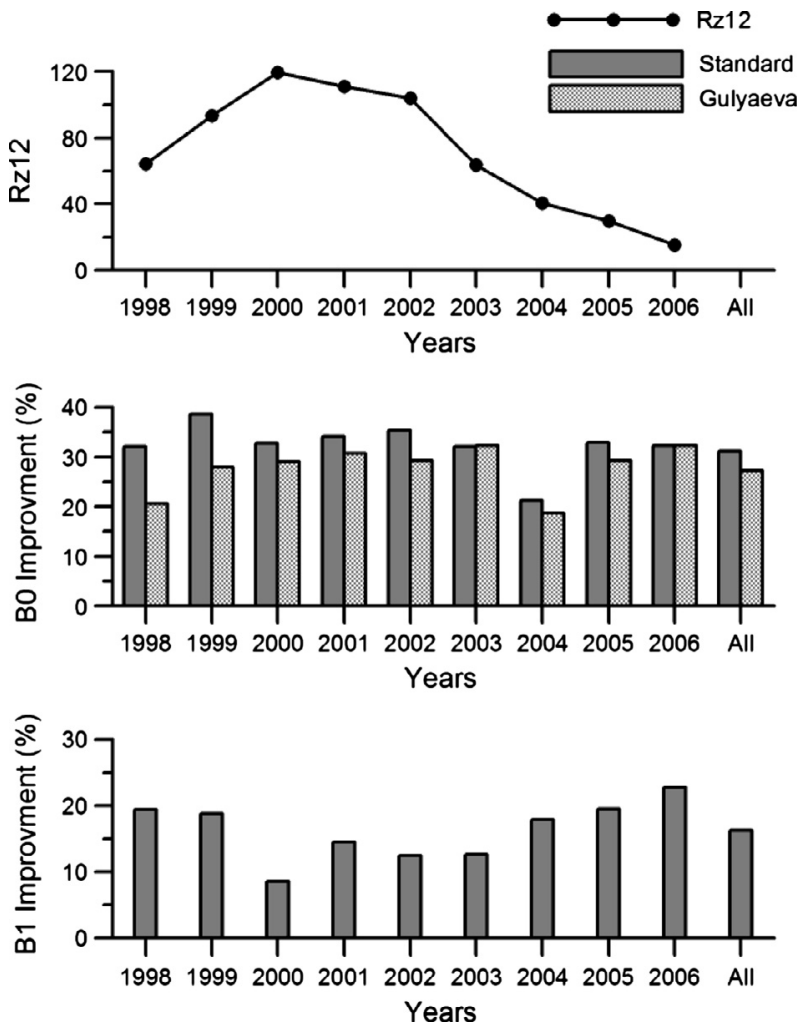

Fig. 3. Comparisons of the root mean square errors (RMSE) between the ionosonde $B_{0}$ data (27 stations) and the Bilitza et al. (2000) model (Standard), the Gulyaeva (1987) model (Gulyaeva) and the Altadill et al. (2009) $B_{0}$ model (SH) for the years 1998-2006. The plot at the top shows the solar activity levels corresponding to each year, the middle plot shows the RSME for $B_{0}$ and the bottom plot shows the RSME for $B_{1}$ (Altadill et al. 2009).

$B_{1}$ models. Altadill et al. (2009) took up the challenge and succeeded in developing a significantly improved model based on data from 27 globally distributed ionosonde stations (DGS or DPS systems) for the years 1998-2006. The model applies spherical harmonics analysis and describes variations with modified dip latitude (modip), LT, month, and sunspot number. Using their $B_{0}$ database they find an improvement of up to $32 \%$ over the Bilitza et al. (2000) model and up to $40 \%$ over the Gulyaeva (1987) model and an improvement of up to $20 \%$ for the $B_{1}$ values. Figure 3 illustrates the significant improvement achieved with the new model in relation to the former bottomside parameter models of IRI. This will also translate into improvements of ionospheric TEC although to a smaller amount because the bottomside contributes only about $15 \%-40 \%$ to the total TEC. The parameter $B_{0}$ is now widely used for defining the bottomside profile thickness. Obrou et al. (2003) find a close correlation of $B_{0}$ from two stations near the magnetic equator with the strength of the equatorial electrojet. Lee (2011) pointed to the anomalous behavior of $B_{0}$ during the recent extreme solar minimum, noting that, while the F2 peak density and height continue to decrease through $2008, B_{0}$ only decreased until 2007 and then started increasing again.

\subsubsection{Auroral boundaries}

At high-latitudes the influx of energetic solar wind and magnetospheric particles results not only in the beautiful display of the 
aurora borealis and australis, but can also have serious detrimental effects on technology in space. A demarcation of this region in IRI has therefore been an important goal of the IRI team (Bilitza 1995). Aurorae are primarily seen within the auroral oval, a region roughly centered at the magnetic poles and typically between 60 and 80 degrees magnetic latitude. The oval is slightly elongated toward the night-side and has its largest extent at local midnight. During magnetic storms the oval expands and moves to lower latitudes. Different methods have been used to define and model auroral boundaries. Feldstein \& Starkov (1967) summarized all-sky imager observations from the International Geophysical Year (IGY) 1957-1958 in a set of representative ovals for seven levels of magnetic activity and Holzworth \& Meng (1975) used a third-order Fourier formula to establish a simple mathematical representation of these ovals. A number of statistical models were developed for the auroral precipitating electron flux and the resulting auroral zone conductances (height-integrated Hall and Pedersen conductivities) based on in situ flux measurements from different satellites (ISIS-2: Wallis \& Budzinski 1981; AE-C, D, E: Spiro et al. 1982; DMSP-F2, F4, P78-1: Hardy et al. 1987; NOAA-TIROS: Fuller-Rowell \& Evans 1987). Auroral boundaries are obtained from such models simply (and also somewhat arbitrarily) by choosing a minimum flux or conductance level. An often used estimate is a conductance of $1 \mathrm{mho}$ or a minimum integral energy flux of $0.25 \mathrm{ergs} \mathrm{cm} \mathrm{cm}^{-2} \mathrm{~s}^{-1}$. Szuszczewicz et al. (1993) and Bilitza (1995) discussed the usage of these models in the IRI framework and present comparisons of the different approaches.

Zhang \& Paxton (2008) recently presented a new approach that is based on global far ultraviolet (FUV) observations by the Global Ultraviolet Imager (GUVI) of the Thermosphere Ionosphere Mesosphere Energetics and Dynamics (TIMED) satellite. The imager provides a much larger database and better global and local time coverage than in situ measurements. GUVI provides cross-track scanned images of the Earth's ultraviolet airglow and FUV auroral emissions. Radiances measured in the N2 Lyman-Birge-Hopfield (LBH) bands (LBHS: 140.0-150.0 nm and LBHL: $165.0-180.0 \mathrm{~nm}$ ) can be used to obtain estimates of the mean energy $(E 0)$ and energy flux (Q) of precipitating electrons (Strickland et al. 1999). Theoretical computations generally proceed in the opposite direction. Starting with $E 0$ and $Q$ (and an assumed spectral distribution) an auroral transport code and airglow code are combined to obtain atmospheric radiances. Zhang \& Paxton (2008) used the Atmospheric Ultraviolet Radiance Integrated Code (AURIC) of Strickland et al. (1999) and the Boltzmann Three Constituent (B3C) of Daniell (1993) to construct tables that relate LBH radiances to the flux characteristics $(E 0, Q)$ of precipitating electrons. Based on GUVI data from 2002 to $2005(\sim 44,000$ images) they developed $E 0$ and $Q$ models describing variations with magnetic latitude and magnetic local time (MLT) for different levels of magnetic activity. Fortuitously, this time period included some of the most intense super-storms of the solar cycle and as a result the Zhang \& Paxton (2008) model covers a much wider range of magnetic activity conditions $(K p=0-9)$ than the Hardy et al. (1987) model $(K p=0-6)$. IRI-2012 uses the equatorward auroral boundary obtained from the Zhang \& Paxton (2008) model at the threshold flux value of $0.25 \mathrm{ergs} \mathrm{cm}^{-2} \mathrm{~s}^{-1}$. Figure 4 shows the predicted decrease of the equatorward boundary and increase of the poleward boundary as the oval expands with increasing magnetic activity.

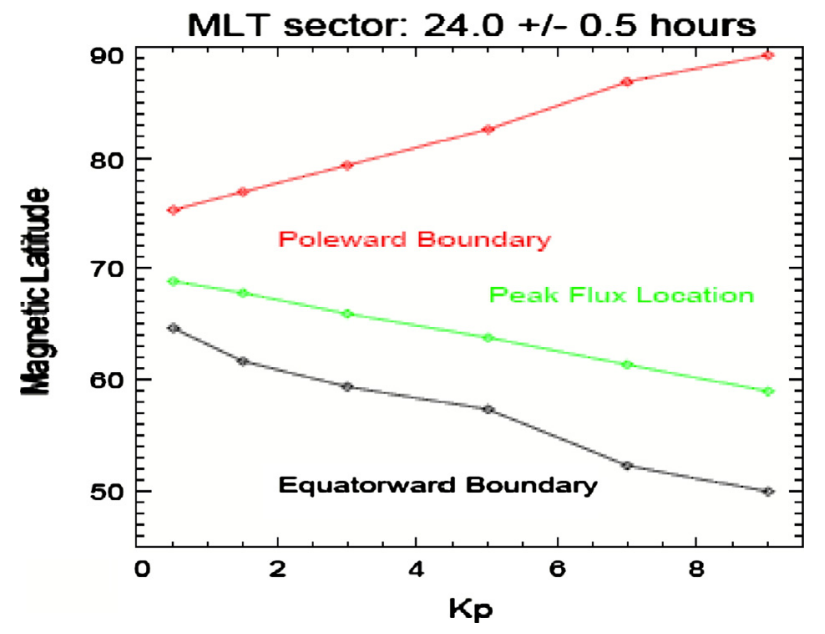

Fig. 4. Equatorward and poleward auroral boundaries and peak flux location obtained with the Zhang \& Paxton (2008) model for different levels of magnetic activity $(K p)$.

Two adjustments had to be made before the model could be included in IRI. The first simply required converting the model from $K p$ dependence to ap dependence because IRI uses the 3-hourly ap index for the description of magnetic storm effects. This is trivial because the two scales are closely correlated. The second adjustment involves the coordinate systems used. The magnetic coordinates used by Zhang \& Paxton (2008) are the Altitude Adjusted CGM coordinates (AACGM) of Baker \& Wing (1989) and Bhavnani \& Hein (1994) while IRI uses the Corrected Geo-Magnetic (CGM) coordinates of Gustafsson et al. (1992). Both coordinate systems use the International Geomagnetic Reference Field (Finlay et al. 2010) to trace from a point in space to the dipole geomagnetic equator and then trace back down along the dipole field line returning to the same altitude (CGM) or to the ground (AACGM) and use the so found geographic coordinates as the CGM or AACGM coordinates for the original point in space. CGM and AACGM coordinates are identical at the Earth surface but differences between the two increase with increasing altitude. The problem is easily resolved by using the Zhang-Paxton model in IRI with the CGM coordinates for altitude zero.

Including auroral boundaries in IRI is a first step toward a better representation of density and temperature features in IRI that are related to these boundaries such as the subauroral density trough and correlated temperature peak. With the availability of real-time GUVI-type measurements, e.g., from TIMED/ GUVI or DMSP/SSUSI, a real-time specification of auroral boundaries can be assimilated into IRI (Zhang et al. 2010).

\subsubsection{Storm-time model for auroral E-region}

Increased particle precipitation during geomagnetic storms can produce significant electron density enhancements in the auroral $E$-region and lead to HF communication interruptions. A first attempt to describe these changes for IRI, was made by McKinnell et al. (2004) and McKinnell \& Friedrich (2007) with their Ionospheric Model for Auroral Zone (IMAZ). IMAZ was developed with EISCAT incoherent scatter radar measurements from 1984 and 1998, plus about 50 rocket flights that measured the electron density using rocket borne radio wave propagation 
Table 2. Storm-to-quiet electron density ratios in the auroral $E$-region.

\begin{tabular}{lccc}
\hline \hline Incoherent scatter radar & Storm period & IRI RMSE & STORM-E RMSE \\
\hline EISCAT-Tromso & $200310 / 21-11 / 02$ & 1.12 & 0.67 \\
EISCAT-Tromso & $200411 / 10-11 / 13$ & 1.07 & 0.35 \\
EISCAT-Tromso & $200612 / 14-12 / 16$ & 1.21 & 0.68 \\
EISCAT-Longyearbyen & $200310 / 21-11 / 02$ & 1.23 & 0.67 \\
EISCAT-Longyearbyen & $200411 / 06-11 / 13$ & 1.37 & 0.89 \\
Sondrestorm & $200310 / 28-10 / 31$ & 1.27 & 0.79 \\
Sondrestorm & $200411 / 10-11 / 13$ & 1.15 & 0.86 \\
Sondrestorm & $200501 / 16-01 / 21$ & 1.15 & 0.81 \\
Sondrestorm & $200612 / 14-12 / 16$ & 1.20 & 0.86 \\
\hline
\end{tabular}

instruments. A Neural Network (NN) was trained with these data evaluating various influencing parameters. Best results were obtained when allowing variations with magnetic local time, riometer absorption, local magnetic $K$ index, F10.7 solar radio flux, and the neutral pressure. Neutral pressure provides a representation of the altitudinal and seasonal variations. The riometer absorption and $K$ index track storm-related changes in the $E$-region. This modeling approach depends on the availability of ground-based radio wave absorption (riometer) measurements and was difficult to seamlessly integrate with the existing quiet-time IRI model. It was provided as a separate, independent software code in IRI-2001 and IRI-2007.

A new model for describing auroral E-region storm effects in IRI was developed by Mertens et al. (2013a, 2013b) based on TIMED SABER data. SABER is the Sounding of the Atmosphere using Broadband Emission Radiometry (SABER) instrument that measures limb radiances in several channels. Mertens et al. (2013a, 2013b) recognized that one of the channels, the $4.3 \mu \mathrm{m}$ radiance measurement, can be a good proxy for characterizing the nighttime $E$-region electron density in response to auroral precipitation. During daytime emissions at this wavelength are dominated by $\mathrm{CO}_{2}$ (v1, v2, v3) vibrationrotation bands during daytime thus providing a $\mathrm{CO}_{2}$ density measurement (the main aim of the SABER $4.3 \mu \mathrm{m}$ measurement). But during nighttime, emissions from vibrationally excited $\mathrm{NO}^{+}$become important and can be reliably separated from the background $\mathrm{CO}_{2}$ (v3) contribution. In comparisons with simultaneous precipitating electron energy flux measurements by the NOAA/POES satellite Mertens et al. (2013a) showed that the $\mathrm{NO}^{+}(\mathrm{v})$ Volume Emission Rates (VER) are an excellent proxy for the incoming energy flux. The stormtime to quiet-time ratio for the electron density is obtained from the corresponding VERs for $\mathrm{NO}^{+}(\mathrm{v})$ :

$$
r=\frac{\mathrm{VER}_{\text {Storm }}}{\mathrm{VER}_{\text {Quiet }}} \approx \frac{\left[\mathrm{NO}^{+}\right]_{\text {Storm }}}{\left[\mathrm{NO}^{+}\right]_{\text {Quiet }}} \approx \frac{[\mathrm{Ne}]_{\text {Storm }}}{[\mathrm{Ne}]_{\text {Quiet }}} .
$$

A power-law function is used to describe the dependence on the 3-hourly ap index

$$
r\left(a p, \lambda_{\mathrm{m}}\right)=\mathrm{C} 1 \times \mathrm{ap}^{\mathrm{C} 2}+\mathrm{C} 3,
$$

with the coefficients $\mathrm{C} 1, \mathrm{C} 2$, and $\mathrm{C} 3$ varying with magnetic latitude $\lambda_{\mathrm{m}}$. Comparisons with nighttime and twilight incoherent scatter radar measurements from EISCAT and Sondrestrom during storm events show good agreement (Mertens et al. 2013b). Table 2 was generated based on these comparisons. One important shortcoming of this model is the limitation to nighttime and twilight hours. Usage in IRI requires a continuous model that does not abruptly start/end at the transition to nighttime/daytime. As a preliminary first-order approach we assume that the nighttime $r\left(a p, \lambda_{\mathrm{m}}\right)$ dependence can be also used throughout the day.

\subsection{Electron temperature}

IRI provides two options for the electron temperature $T_{e}$. In both cases the model built-up is the same, using a spherical harmonics representation of the global temperature variations at fixed heights and Epstein functions to describe the altitudinal variation. When this approach was first applied by Bilitza (1985) and Bilitza et al. (1985), it was based on the AE-C, ISIS-1, and ISIS-2 global parameterizations of Brace \& Theis (1981) at $300 \mathrm{~km}, 400 \mathrm{~km}, 1400 \mathrm{~km}$, and $3000 \mathrm{~km}$ and the AEROS-A model of Spenner \& Plugge (1979) at $600 \mathrm{~km}$. Truhlik et al. (2000) more recently utilized the global measurements of the Interkosmos 19, 24, and 25 satellites to develop global models at $350,550,650,1400$, and $2000 \mathrm{~km}$ with a more detailed description of the diurnal variation including the early morning overshoot that was not well represented in the earlier models. Both of these models describe the variations with magnetic latitude and magnetic local time (MLT) providing different sets of coefficients for different seasons. These models have performed well in comparisons with satellite and incoherent scatter radar measurements. Their main shortcoming is the fact that they do not include variations with solar activity. There are a number of reasons why modeling of the solar activity variations of the electron temperature is a difficult task: (1) While most ionospheric parameters increase with solar activity $T_{e}$ can increase, decrease, or stay constant depending on the altitude, latitude, time of day, or season. This is because $T_{e}$ is determined by the balance of heating through photoelectrons that are created by the solar EUV irradiance, cooling through collisions with neutrals and ions, and heat conduction along magnetic field lines. All three terms increase with solar activity due to the increase in EUV flux, neutral density, neutral temperature, and electron and ion densities. Since the three terms compensate each other the net result can be a $T_{e}$ increase, decrease, or no change at all. An example is shown in Figure 5 where $T_{e}$ averages from satellite in situ measurements are plotted versus invdip latitude for three levels of solar activity (low, medium, high) at $550 \mathrm{~km}( \pm 50 \mathrm{~km})$ for solstice (left) and equinox (right). For equinox $T_{e}$ increases with solar activity at high and low latitudes, decreases at middle latitudes, and is near constant in between these regions. In the summer hemisphere the $T_{e}$ correlation with solar activity is positive while on the winter side it is negative. (2) Inconsistencies remain among various data sets especially in regimes of low electron density because most $T_{e}$ measurement techniques depend critically on the presence of a sufficient number of electrons. An example is shown in Figure 6 where the difference between DMSP Langmuir probe measurements and simultaneous measurements by the ground 


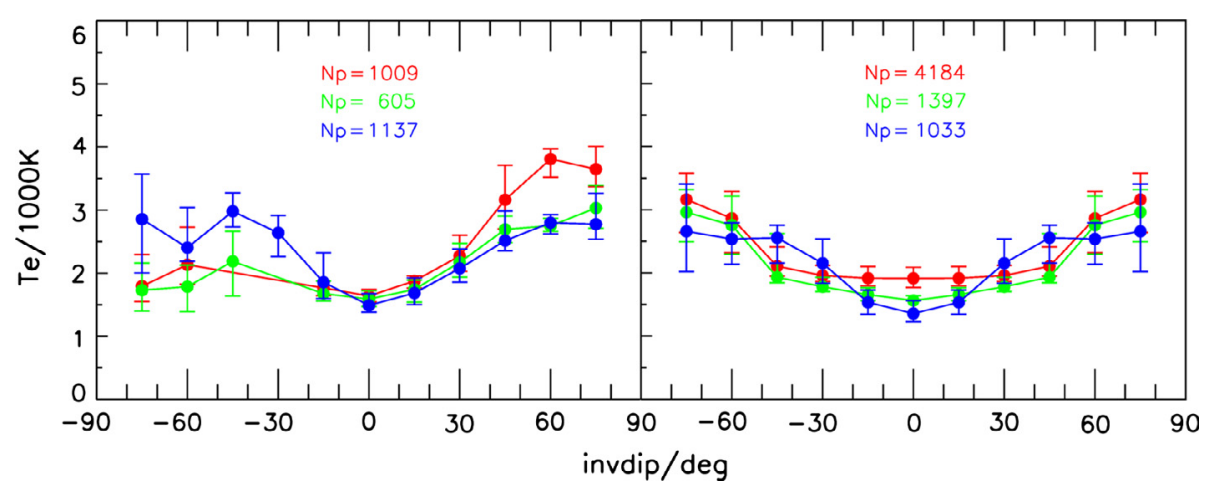

Fig. 5. Equinox (left) and solstice (right) noontime electron temperatures versus invdip latitude at $550 \mathrm{~km}$ for three levels of solar activity (blue, low, PF10.7 < 110; green, medium, $110<\mathrm{PF} 10.7<180$; red, high, PF10.7 > 180). Data shown are from satellite in situ measurements giving the median plus upper and lower quartiles. $N p$ is total number of measurements for each curve.

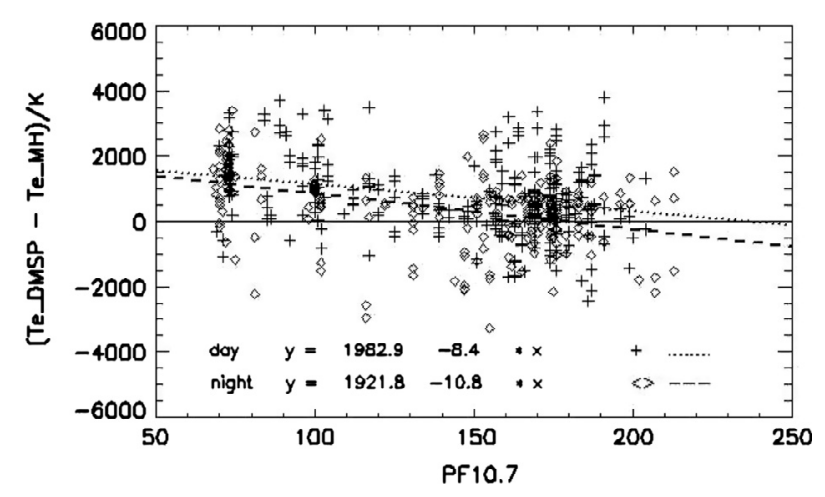

Fig. 6. Difference between DMSP probe Te measurements and simultaneous Millstone Hill incoherent scatter measurements versus the solar activity index PF10.7 $=(\mathrm{F} 10.7 \mathrm{D}+\mathrm{F} 10.781) / 2$ with F10.7D the daily solar radio flux index F10.7 and F10.7 81 the 81 day average of F10.7. The 540 coincidences from the time period 1996 to 2006 are separated into daytime $(+)$ and night-time $(\diamond)$ and also include a least-square fitted linear approximation (broken curve) with the formula given at the bottom.

incoherent scatter radar at Millstone Hill are plotted versus solar activity, revealing large discrepancies at low solar activities (and therefore low electron density) with the probe data exceeding the radar data by about $1000 \mathrm{~K}(100 \%)$. Bilitza et al. (2007) and Truhlik et al. (2009) have studied this complex solar activity behavior of the electron temperature with a large database of satellite in situ measurements and with the help of the Field Line Interhemispheric Plasma (FLIP) physical model (Richards 2001) and the empirical model of Zhang et al. (2005) that represents many years of Millstone Hill incoherent scatter radar (ISR) measurements. Their work resulted in a new model for $T_{e}$ (Truhlik et al. 2012) that now describes solar activity variations and is included in the latest version of the IRI model.

\subsection{Ion composition}

The ion composition has been the step-child of IRI development activities, partly because of the limited amount of available data and still existing discrepancies between ground and space observations, and partly because of the much smaller community of IRI users that require information about the ionospheric ion composition. As with many of its parameters, the IRI user can choose between two options for the ion composition. The older version is based on the work of Danilov \&
Smirnova (1995) in the bottomside and of Danilov \& Yaichnikov (1985) in the topside ionosphere using a compilation of Russian rocket measurements including high-altitude rockets that cover topside altitudes. The models give the percentage of $\mathrm{O}^{+}, \mathrm{H}^{+}$, $\mathrm{N}^{+}, \mathrm{He}^{+}, \mathrm{NO}^{+}, \mathrm{O}_{2}^{+}$, and Cluster ions as a function of solar zenith angle, latitude, season, and solar activity. Considering the limited database the models have performed quite well and gave IRI users a first estimate of the distribution of ions in the ionosphere. A newer topside version was developed by Triskova et al. (2003) and is included in IRI as the recommended option since IRI-2007. This newer model takes advantage of the better global coverage provided by satellite ion mass spectrometer measurements (Interkosmos-24, AE-C, AE-E) and uses the invdip latitude coordinate that is close to the magnetic inclination (dip) near the magnetic equator and gets close to invariant latitude at higher latitudes, and thus correlates well with the observed variation patterns of the topside ions (Truhlik et al. 2004). Compared to the older Danilov \& Yaichnikov (1985) model, the newer model also provides a more detailed description of variations over the year, and uses the more appropriate Magnetic Local Time (MLT) to describe diurnal changes instead of the solar zenith angle that is more suited for the lower ionosphere. With IRI-2012 a newer ion composition model is now also introduced for the bottomside ionosphere. The model of Richards et al. (2010) makes use of the fact that the photochemistry in the lower ionosphere is well-established as comparisons between model calculations and measurements have proven. So by normalizing the ion densities obtained with the FLIP model photochemistry to the IRI electron densities, Richards et al. (2010) obtain a new description of the composition of molecular ions and $\mathrm{O}^{+}$in the lower ionosphere. Their comparisons with AE-C ion density measurements show good agreement and also highlight the significant improvement the new model achieves over the older Danilov \& Smirnova (1995) model. Model caveats are, that it does not account for auroral particle precipitation nor for rapid convection. Partly these limitations will be overcome by the normalization with a total ion density (= electron density) that includes these effects.

\subsection{Other improvements in IRI-2012}

As requested by COSPAR the IRI plasma temperatures should be in thermal equilibrium with the CIRA neutral temperature at $120 \mathrm{~km}$ and below, and should not fall below the neutral temperature at any altitude. The IRI program therefore had to include the computation of the CIRA neutral temperature. With 


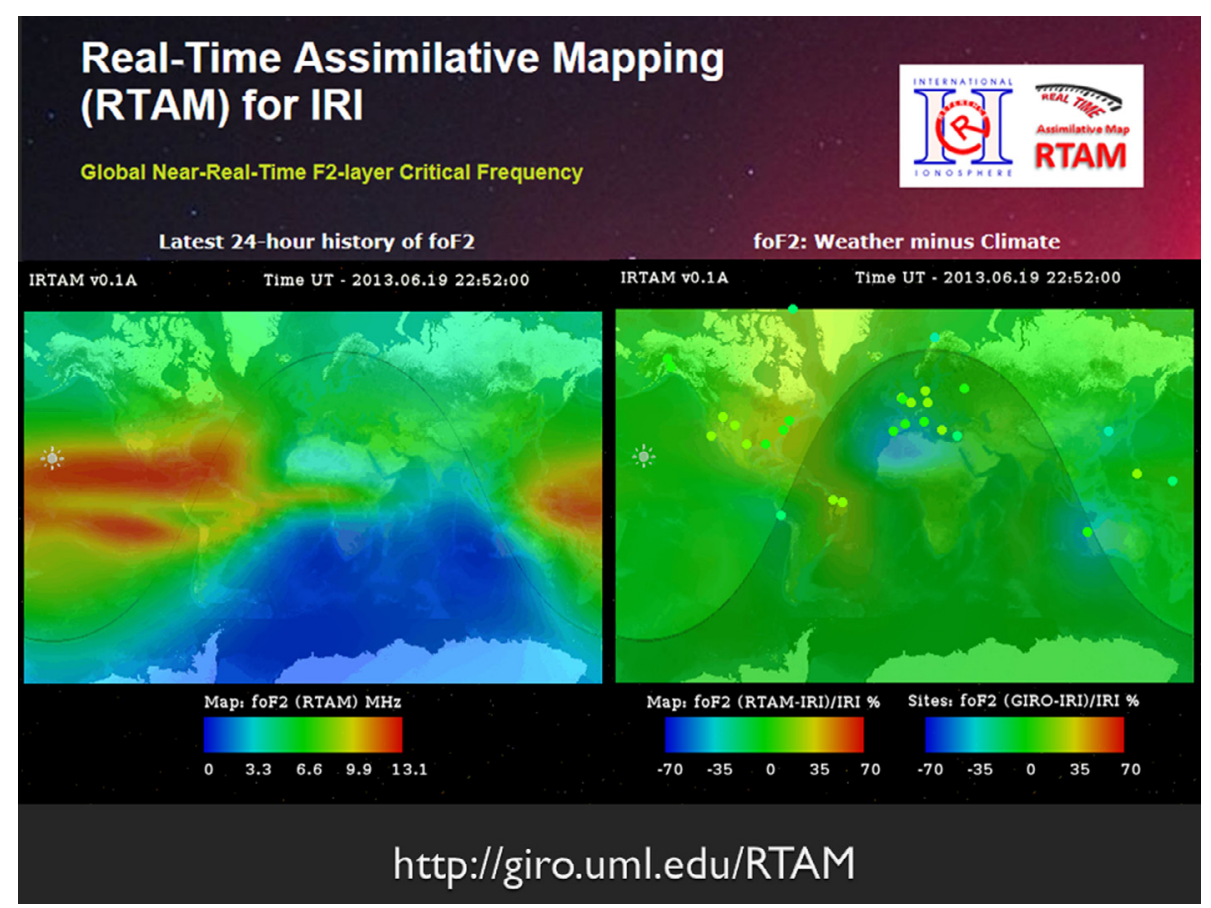

Fig. 7. World maps of plasma frequency foF2 obtained with IRI RTAM by assimilating data from the Global Ionospheric Radio Observatory (GIRO) into the IRI model for foF2. The left panel shows the final map. The right panel shows the GIRO digisonde stations (circles) that contributed and the color in the circle percentage difference between IRI and the GIRO measurements. The color in the rest of the right panel shows the percentage difference between RTAM and IRI.

IRI-2012 the CIRA model has now been upgraded to the NRLMSIS-00 model (Picone et al. 2002) in concurrence with the decisions made by the CIRA Working Group. This is also of importance for the new model for the bottomside ion composition of Richards et al. (2010) that requires neutral densities for its photochemistry computations.

IRI-2010 makes use of the latest version of the International Geomagnetic Reference Field (Finlay et al. 2010) for its computation of magnetic coordinates, using the latest sets of coefficients for 2010 and beyond to accurately represent the changes in the Earth's magnetic field. For a better representation of the latitudinal changes of ionospheric parameters at high-latitudes IRI-2012 now also includes the Corrected Geomagnetic Coordinates (CGM) of Gustafsson et al. (1992) that are needed, for example, for the representation of auroral boundaries.

\section{Real-time IRI}

IRI represents the monthly average behavior of the ionosphere at a given place and time, for a given level of solar activity. So IRI can predict the changes from one month to the next but not from day to day. More and more applications, however, require a description of the day-to-day variations. In some cases an estimate of the expected range of variability is all that is needed and there is an IRI effort underway to include a quantitative description of ionospheric variability in IRI in the form of the monthly standard deviation (Araujo-Pradere et al. 2004, 2005; Bilitza et al. 2004). A more accurate description of the changes from day to day requires the use of real-time data and of updating or assimilation techniques to combine IRI with these data and in the process produce the Real-Time IRI (IRI-RT).
Most updating algorithms use the computation of an ionospheric-effective solar index by adjusting IRI predictions to ionosonde measurements (Bilitza et al. 1997), or to GPS Total Electron Content (TEC) maps (Komjathy et al. 1998), or to GPS slant TEC data (Hernandez-Pajares et al. 2002). Different techniques have been used to assimilate data into IRI. Fridman et al. (2006) used the Tikhonov methodology with IRI and GPS data. The Electron Density Assimilative Model (EDAM) approach of Angling et al. (2009) is based on a weighted, damped least mean squares estimation (also referred to as Best Linear Unbiased Estimation - BLUE) and assimilates mostly GPS data into IRI-2007. Good results were obtained by Yue et al. (2012) using a Kalman filter technique to assimilate GPS data, radio occultation data (CHAMP, GRACE, COSMIC, SAC-C, Metop-A, and TerraSAR-X), and Jason-1 and 2 altimeter TEC measurements into IRI-2007. Schmidt et al. (2008) represent the difference between GPS data and IRI globally and regionally with a multidimensional expansion in B-spline functions. Combing assimilation and updating techniques, Pezzopane et al. (2011) first determine a ionospheric-effective sunspot number from comparing IRI to ionosonde F2 peak parameter (foF2, M(3000)F2) measurements and then after fully analyzing the ionograms applied a Kriging technique to assimilate the full electron density profile into IRI-2007. The IRI Real-Time Assimilative Mapping (IRTAM) of Galkin et al. (2012) is based on plasma frequency (foF2) measurements by the worldwide network of Digisonde stations (the Global Ionospheric Radio Observatory - GIRO) and employs a linear optimization technique to obtain an improved global representation of foF2 for IRI every $15 \mathrm{~min}$ (http:/giro.uml.edu/ RTAM). An example is shown in Figure 7. Zhang et al. (2010) developed an algorithm for updating the IRI auroral 
Table 3. Percentage of JGR, GRL, SW, and RS papers using IRI.

\begin{tabular}{lcccc}
\hline \hline & \multicolumn{4}{c}{ Percentage of papers using IRI } \\
\cline { 2 - 5 } & JGR & GRL & SW & RS \\
\hline 2009 & $5.0 \%$ & $3.6 \%$ & $0.0 \%$ & $10.5 \%$ \\
2010 & $5.6 \%$ & $4.7 \%$ & $5.6 \%$ & $11.8 \%$ \\
2011 & $7.1 \%$ & $1.6 \%$ & $8.1 \%$ & $14.2 \%$ \\
2012 & $8.0 \%$ & $1.7 \%$ & $9.5 \%$ & $15.1 \%$ \\
\hline
\end{tabular}

JGR $=$ Journal Geophysical Research-Space, $\mathrm{SW}=$ Space Weather journal, GRL $=$ Geophysical Research Letters, RS $=$ Radio Science.

boundaries (see Sect. 2.1.2) with real-time measurements by the GUVI instrument on the TIMED satellite and the SSUSI instrument on the DMSP satellite.

Special IRI Real-Time workshops were held in 2009 and 2012 to discuss the feasibility of the different methods and to decide on the best approach toward the IRI-RT. These workshops discussed two related but distinct objectives of the concept of "real-time". The first is to provide an historical record of the state of the ionosphere. This is a post-processing activity that does not require the analysis to be done in realtime, but is more akin to the concept of "re-analysis" that has been applied to tropospheric weather. The second objective is to perform the assimilation in real-time, pushing the IRI climatological state toward the actual state using all available observations. The two activities are related because they are built upon the same concept, to combine model and data with data assimilation techniques. There are several motivations for these two activities. Providing an accurate record of the state of the ionosphere over an extended period would contribute a tremendous resource for scientific studies. There is also the need for real-time ionospheric specification and forecast for space weather applications. By using IRI at the heart of a real-time data assimilation system, it benefits from the years of development work that are behind this internationally recognized ionospheric reference model.

\section{Measures of success}

IRI has become a household name in ionospheric physics. It is internationally accepted as the standard for ionospheric parameters and is used by a wide spectrum of novice and expert users for applications in science, engineering, and education. The international recognition of IRI is documented by the 1999 URSI resolution (see Table 1) and by the fact that IRI is the standard for the ionosphere for the European Cooperation for Space Standardization (ECSS 2008) and for the International Standardization Organization (ISO; Gulyaeva \& Bilitza 2011). The wide scientific usage of the IRI model can be measured by the number of scientific publications that acknowledge the use of IRI. Table 3 shows the percentage of papers that used IRI in the years 2009 through 2012 in the science journals Journal of Geophysical Research (JGR) - Space, Geophysical Research Letters (GRL), Space Weather (SW) journal, and Radio Science (RS). These numbers were obtained by an automated keyword search of the full text of all articles and then a manual inspection of the found articles, to make sure IRI was used and not only referenced. Except for GRL, the percentage of papers using IRI is increasing from year to year, reaching $8 \%$

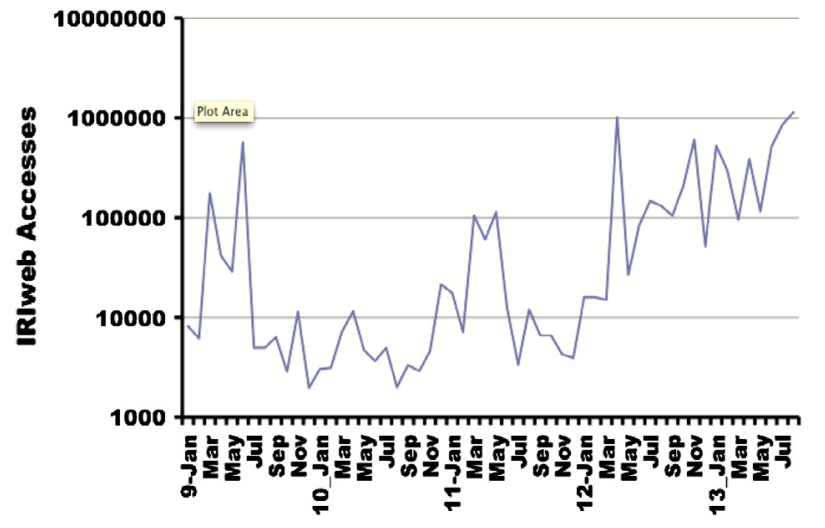

Fig. 8. Monthly accesses to the IRIweb online interface from January 2009 to July 2013.

for JGR, 9.5\% for SW and an amazing 15.1\% for RS in 2012; so every 7th RS paper in 2012 relied on IRI to achieve its science goals. In addition to these four journals there are many other journals that have articles describing work that relies on the IRI model. A wider literature search reveals 133 citations of the IRI-2007 paper (Bilitza \& Reinisch 2008) in 2011 and 138 citations in 2012 across a wide spectrum of journals, 23 in all, including GPS Solutions, Computer Physics Communications, Solar Physics, Applied Optics, Plasma Science and Technology, Computers \& Geosciences, to name just a few, underlining the wide spectrum of IRI applications. Finally, we can also see a remarkable increase in the number of accesses to the IRIWeb, the web interface for computing IRI parameters that is shown in Figure 8. Accesses show roughly a 10-fold increase from year to year, recently reaching the 1 million per month mark.

The IRI model has gained this high level of acceptance and trust because it has been extensively evaluated with large volumes of data from ground and space measurement techniques. When discrepancies were found, the IRI team made it its highest priority to improve the model to accurately represent the new data source. Many of these comparisons and if necessary consecutive improvement studies can be found in the series of special IRI-related issues of Advances in Space Research that were mentioned in the Introduction. Recently the Coupling, Energetics, and Dynamics of Atmospheric Regions (CEDAR) program of the National Science Foundation (NSF) initiated the Electrodynamics Thermosphere Ionosphere (ETI) Challenge to assess the accuracy of ionosphere/thermosphere models in reproducing ionosphere and thermosphere parameters. A total of nine events and five physical parameters were selected to compare observations with the predictions by 10 of the most well established ionosphere/thermosphere models. IRI was the only data-based model, all others were physics-based models and two of these in addition employed data assimilation techniques with GPS data for the respective event periods. IRI performed very well in this challenge and was best or one of the three best in all categories considered by this challenge (Shim et al. 2011, 2012). It is noteworthy that in several cases IRI performed better than the physics-based models with data assimilation capabilities. As mentioned in the previous section the accuracy of IRI can be increased significantly with data assimilation techniques and IRI with data assimilation would therefore have done extremely well in the CEDAR ETI Challenge. 
Success of an international science collaboration should not only be measured by the applicability, accuracy, and wide usage of the scientific results of the endeavor, that we presented above, but also in as much as it succeeded in involving scientists from many countries worldwide including developed and developing countries, and in as much as it helped initiate multilateral science projects and provided an opportunity for emerging science programs to participate in an international program. The IRI project and program has been highly successful in all of these areas. Many of its bi-annual workshops were held in developing countries providing scientists from these countries with the opportunity to get involved in IRI-related science projects with other countries. The IRI project, on the other hand, benefitted by getting access to new data sources from these countries.

\section{Conclusions}

Empirical models play an important role in all parts of the SunEarth environment. They give the scientist, engineer, and educator easy access to a condensed form of the available empirical evidence for a specific parameter, optimally, being based on all reliable data sources that exist for the parameter. Examples of such widely used models are the International Geomagnetic Reference Field (IGRF) model for Earth's magnetic field (Finlay et al. 2010) and the Mass Spectrometer and Incoherent Scatter (MSIS) model for Earth's Atmosphere (Picone et al. 2002). The ionospheric equivalent to these models is the International Reference Ionosphere (IRI). The IRI project is an excellent example of a successful international science collaboration that has operated for several decades and has resulted in an ionospheric model that is widely acknowledged as the standard ionospheric model and now also close to becoming an ISO standard (Gulyaeva \& Bilitza 2011). It has also helped a large multitude of both novice and expert users ranging from ham radio operators to satellite/rocket instrument designers to operators of Earth observing satellites.

Since initiated by COSPAR and URSI in 1969, IRI has been steadily improved with newer data and better modeling techniques leading to the release of a number of key editions of the model including the IRI-78 (Rawer et al. 1978a, 1978b), IRI-85 (Bilitza 1986), IRI-1990 (Bilitza 1990), IRI2000 (Bilitza 2001), and IRI-2007 (Bilitza \& Reinisch 2008). In the preceding sections we have presented the latest version IRI-2012 and briefly discussed a new effort to develop a Real-Time IRI by combining IRI with real-time data using updating or assimilation techniques. The IRI success story is documented by the increasing rate of accesses to the IRIweb interface, recently reaching 1 million per month, and by the increasing number of science papers that acknowledge the use of the IRI model, e.g., 8\% of all 2012 Journal of Geophysical Research papers and $15 \%$ of all 2012 Radio Science papers. The special ingredients that made the IRI such a success story are:

1. Working group members who provide a good, balanced cross-section in terms of the representation of different countries and continents (see Fig. 1) as well as in terms of the representation of different measurement techniques. This turned out to be a great asset in gaining access to essentially all reliable ground and space data sets for ionospheric parameters.

2. Annual IRI Workshops that are the main venue for discussing improvements and enhancements to the model and that are the catalyst for a multitude of international collaborations whose goal was to improve specific aspects of the model. A trademark of these informal meetings is the "Final Discussion" session where the IRI team decides on the improvements and additions to be included in the next version of the model, and where "volunteers" are enlisted to investigate new data sources and specific modeling questions for future model updates.

3. Publication of the workshop papers initially in Space Research, and later in Advances in Space Research that has resulted in an excellent record of the IRI activity and has produced a unique series of articles documenting the international efforts in ionospheric modeling.

4. An easy to use, fast, open source software and web interface.

Acknowledgements. We acknowledge the contributions of IRI Working Group members to the IRI effort and the many users of the model who have provided valuable feedback.

\section{References}

Altadill, D., J.M. Torta, and E. Blanch, Proposal of new models of the bottom-side B0 and B1 parameters for IRI, Adv. Space Res., 43, 1825-1834, DOI: 10.1016/j.asr.2008.08.014, 2009.

Angling, M.J., J. Shaw, A.K. Shukla, and P.S. Cannon, Development of an HF selection tool based on the Electron Density Assimilative Model near-real-time ionosphere, Radio Sci., 44, RS0A13, DOI: 10.1029/2008RS004022, 2009.

Araujo-Pradere, E.A., T.J. Fuller-Rowell, and D. Bilitza, Ionospheric variability for quiet and perturbed conditions, $A d v$. Space Res., 34 (9), 1914-1921, DOI: 10.1016/j.asr.2004.08.007, 2004.

Araujo-Pradere, E.A., T.J. Fuller-Rowell, M.V. Codrescu, and D. Bilitza, Characteristics of the ionospheric variability as a function of season, latitude, local time, and geomagnetic activity, Radio Sci., 40, RS5009, 1-15, DOI:10.1029/2004RS003179, 2005.

Baker, K.B., and S. Wing, A new magnetic coordinate system for conjugate studies at high latitudes, J. Geophys. Res., 94 (A7), 9139-9143, DOI: 10.1029/JA094iA07p09139, 1989.

Bhavnani, K.H., and C.A. Hein, An improved algorithm for computing altitude dependent corrected geomagnetic coordinates, Scientific Report PL-TR-94-2310, Phillips Laboratory: 29 Randolph Road, Hanscom AFB, MA 01731-3010, USA, 1994.

Bilitza, D., Implementation of the new electron temperature model in IRI, Adv. Space Res., 5 (10), 117-122, DOI: 10.1016/0273-1177(85)90193-0, 1985.

Bilitza, D., International reference ionosphere: recent developments, Radio Sci., 21, 343-346, DOI: 10.1029/RS021i003p00343, 1986.

Bilitza, D. and International Reference IonosphereNational Space Science Data Center, Report 90-22, Greenbelt, Maryland, USA, 1990.

Bilitza, D., Including auroral boundaries in the IRI model, $A d v$. Space Res., 16 (1), 13-16, DOI: 10.1016/0273-1177(95)00093-T, 1995.

Bilitza, D., International Reference ionosphere - Status 1995/96, Adv. Space Res., 20 (9), 1751-1754, 1997.

Bilitza, D., International Reference Ionosphere 2000, Radio Sci., 36 , 261-275, DOI: 10.1029/2000RS002432, 2001. 
Bilitza, D., and B.W. Reinisch, International Reference Ionosphere 2007: Improvements and new parameters, $A d v$. Space Res., 42 (4), 599-609, DOI: 10.1016/j.asr.2007.07.048, 2008.

Bilitza, D., L.H. Brace, and R.F. Theis, Modelling of ionospheric temperature profiles, Adv. Space Res., 5 (7), 53-58, 1985.

Bilitza, D., S. Bhardwaj, and C. Koblinsky, Improved IRI predictions for the GEOSAT time period, Adv. Space. Res., 20 (9), 1755-1760, 1997.

Bilitza, D., S. Radicella, B. Reinisch, J. Adeniyi, M. Mosert, S. Zhang, and O. Obrou, New B0 and B1 models for IRI, Adv. Space. Res., 25 (1), 89-95, 2000.

Bilitza, D., O. Obrou, J. Adeniyi, and O. Oladipo, Variability of foF2 in the equatorial ionosphere, Adv. Space Res., 34 (9), 1901-1906, DOI: 10.1016/j.asr.2004.08.004, 2004.

Bilitza, D., V. Truhlik, P. Richards, T. Abe, and L. Triskova, solar cycle variation of mid-latitude electron density and temperature: Satellite measurements and model calculations, Adv. Space Res., 39 (5), 779-789, DOI: 10.1016/j.asr.2006.11.022, 2007.

Blanch, E., D. Arrazola, D. Altadill, D. Buresova, and M. Mosert, Improvement of IRI B0, B1 and D1 at mid-latitudes using MARP, Adv. Space Res., 39 (5), 701-710, DOI: 10.1016/j.asr.2006.08.007, 2007.

Brace, L.H., and R.F. Theis, Global empirical models of ionospheric electron temperature in the upper F-region and plasmasphere based on in situ measurements from atmosphere explorer C, ISIS 1 and ISIS 2 satellites, J. Atmos. Terr. Phys., 43, 1317-1343, 1981.

Chen, H., L. Liu, W. Wan, B. Ning, and J. Lei, A comparative study of the bottom side profile parameters over Wuhan with IRI-2001 for 1999-2004, Earth Planets Space, 58, 601-605, 2006.

CIRA, COSPAR International Reference Atmosphere, Amsterdam, The Netherlands: North-Holland Publications, 1961.

Daniell Jr., R.E., Modeling of optical signatures of electron spectra in the ionospheric heating experiments. In : Proceedings of the Seventh International Ionospheric Effects Symposium, Arlington, Virginia, USA, SRI International, 6B/5/1, 1993.

Danilov, A.D., and A.P. Yaichnikov, A new model of the ion composition at 75 to $1000 \mathrm{~km}$ for IRI, Adv. Space Res., 5 (7), 75-79, 107-108, 1985.

Danilov, A.D., and N.V. Smirnova, Improving the 75 to $300 \mathrm{~km}$ ion composition model of the IRI, Adv. Space Res., 15 (2), 171-177, 1995.

ECSS, European Cooperation for Space Standardization, System Engineering: Space Environment, ECSS-E-ST-10-04C, Noordwijk, The Netherlands, 2008.

Feldstein, Y.I., and G.V. Starkov, Dynamics of auroral belt and polar geomagnetic disturbances, Planet. Space Sci., 15, 209, 1967.

Finlay, C.C., S. Maus, C.D. Beggan, T.N. Bondar, and A. Chambodut, et al., International Geomagnetic Reference Field: the eleventh generation, Geophys. J. Int., 183, 1216-1230, DOI: 10.1111/j.1365-246X.2010.04804.x, 2010

Fridman, S.V., L.J. Nickisch, M. Aiello, and M. Hausman, Real-time reconstruction of the three dimensional ionosphere using data from a network of GPS receivers, Radio Sci., 41, RS5S12, DOI: 10.1029/2005RS003341, 2006.

Fuller-Rowell, T.J., and D.S. Evans, Height-integrated Pedersen and Hall conductivity patterns inferred from the TIROS-NOAA satellite data, J. Geophys. Res., 92, 7606-7618, 1987.

Galkin, I.A., B.W. Reinisch, X. Huang, and D. Bilitza, Assimilation of GIRO data into a real-time IRI, Radio Sci., 47, RS0L07, DOI: $10.1029 / 2011$ RS004952, 2012.

Gulyaeva, T., Progress in ionospheric informatics based on electron density profile analysis of ionograms, Adv. Space Res., 7 (6), $39-48,1987$.

Gulyaeva, T., and D. Bilitza, Towards ISO Standard Earth Ionosphere and Plasmasphere Model. In : New developments in the standard model, R.J., Larsen, Editor, Nova Science Publishers, Hauppauge, NY, USA, 2011.

Gustafsson, G., N.E. Papitashvili, and V.O. Papitashvili, A revised corrected geomagnetic coordinate system for epochs 1985 and 1990, J. Atmos. Terr. Phys., 54, 1609-1631, 1992.
Hardy, D.A., M.S. Gussenhoven, R. Raistrick, and W.J. McNeil, Statistical and functional representation of the pattern of auroral energy flux, number flux, and conductivity, J. Geophys. Res., 92, 12275-12294, 1987.

Hernandez-Pajares, M., J. Juan, J. Sanz, and D. Bilitza, Combining GPS measurements and IRI model values for Space Weather specification, Adv. Space Res., 29 (6), 949-958, 2002.

Holzworth, R.H., and C.I. Meng, Mathematical representation of the auroral oval, Geophys. Res. Lett., 2, 337-380, 1975.

Immel, T.J., E. Sagawa, S.L. England, S.B. Henderson, M.E. Hagan, S.B. Mende, H.U. Frey, C.M. Swenson, and L.J. Paxton, Control of equatorial ionospheric morphology by atmospheric tides, Geophys. Res. Lett., 33, L15108, DOI: 10.1029/2006GL026161, 2006.

Komjathy, A., R. Langley, and D. Bilitza, Ingesting GPS-Derived TEC Data into the international reference ionosphere for single frequency radar altimeter ionospheric delay corrections, $A d v$. Space Res., 22 (6), 793-802, 1998.

Lee, C.-C., Equatorial B0 anomaly in September under extremely low solar activity, J. Geophys. Res., 116, A05325, DOI: 10.1029/ 2010JA016394, 2011

Lee, C.-C., and B.W. Reinisch, Quiet-condition hmF2, NmF2, and B0 variations at Jicamarca and comparison with IRI-2001 during solar maximum, J. Atmos. Sol. Terr. Phys., 68, 2138-2146, DOI: 10.1016/j.jastp.2006.07.007, 2006.

Lee, C.-C., B.W. Reinisch, S.-Y. Su, and W.S. Chen, Quiet-time variation of F2-layer parameters at Jicamarca and comparison with IRI-2001 during solar minimum, J. Atmos. Sol. Terr. Phys., 70, 184-192, DOI: 10.1016/j.jastp.2007.10.008, 2008.

Lei, J., L. Liu, W. Wan, S.R. Zhang, and J.M. Holt, A statistical study of ionospheric profile parameters derived from Millstone Hill incoherent scatter radar measurements, Geophys. Res. Lett., 31, L14804, DOI: 10.1029/2004GL020578, 2004.

Lühr, H., and C. Xiong, The IRI2007 model overestimates electron density during the 23/24 solar minimum, Geophys. Res. Lett., 37, L23101, DOI: 10.1029/2010GL045430, 2010.

Lühr, H., K. Häusler, and C. Stolle, Longitudinal variation of $F$ region electron density and thermospheric zonal wind caused by atmospheric tides, Geophys. Res. Lett., 34, L16102, DOI: 10.1029/2007GL030639, 2007.

McKinnell, L.A., M. Friedrich, and R.J. Steiner, A new approach to modeling the daytime lower ionosphere at auroral latitudes, $A d v$. Space Res., 34 (9), 1943-1948, DOI: 10.1016/j.asr.2004.05.005, 2004.

McKinnell, L.A., and M. Friedrich, A neural network-based ionospheric model for the auroral zone, J. Atmos. Sol. Terr. Phys., 69, 1459-1470, DOI: 10.1016/j.jastp.2007.05.003, 2007.

McNamara, L.F., J.M. Retterer, C.R. Baker, G.J. Bishop, D.L. Cooke, C.J. Roth, and J.A. Welsh, Longitudinal structure in the CHAMP electron densities and their implications for global ionospheric modeling, Radio Sci., 45, RS2001, DOI: 10.1029/2009RS004251, 2010.

Mertens, C.J., Xiaojing. Xu, D. Bilitza, M.G. Mlynczak, and J.M. Russell III, Empirical STORM-E Model: I. Theoretical and observational basis, Adv. Space Res., 51 (4), 554-574, DOI: 10.1016/j.asr.2012.09.009, 2013a.

Mertens, C.J., X.J. Xu, D. Bilitza, M.G. Mlynczak, and J.M. RussellIII, Empirical STORM-E Model: II. Geomagnetic corrections to nighttime ionospheric e-region electron densities, $A d v$. Space Res., 51 (4), 575-598, DOI: 10.1016/j.asr.2012.09.014, 2013.

Obrou, O.K., S.M. Radicella, and J.O. Adeniyi, The equatorial electrojet and the profile parameters B0 and B1 around midday, J. Atmos. Sol. Terr. Phys., 65, 299-304, DOI: 10.1016/S1364-6826(02)00336-X, 2003.

Pezzopane, M., M. Pietrella, A. Pignatelli, B. Zolesi, and L.R. Cander, Assimilation of autoscaled data and regional and local ionospheric models as input sources for real-time 3-D International Reference Ionosphere modeling, Radio Sci., 46, RS5009, DOI: 10.1029/2011RS004697, 2011. 
Picone, J.M., A.E. Hedin, D.P. Drob, and A.C. Aikin, NRLMSISE00 empirical model of the atmosphere: Statistical comparisons and scientific issues, J. Geophys. Res., 107 (A12), 1468, DOI: 10.1029/2002JA009430, 2002.

Rawer, K., S. Ramakrishnan, and D. Bilitza, Preliminary reference profiles for electron and ion densities and temperatures proposed for the International Reference Ionosphere, Scientific Report W.B. 2, Institut für physikalische Weltraumforschung: Freiburg, Germany, 1975

Rawer, K., D. Bilitza, and S. Ramakrishnan, International Reference Ionosphere 1978, Brussels, Belgium, International Union of Radio Science (URSI), 1978a.

Rawer, K., D. Bilitza, and S. Ramakrishnan, Goals and status of the international reference ionosphere, Rev. Geophys., 16, 177-181, 1978b.

Rawer, K., V. Lincoln, and R. Conkright, Editors, International Reference Ionosphere - IRI 79, Report UAG-82, World Data Center A for Solar-Terrestrial Physics, Boulder, Colorado, USA, 1981

Richards, P.G., Seasonal and solar cycle variations of the ionospheric peak electron density: comparison of measurement and models, $J$. Geophys. Res., 106, 12803-12819, DOI: 10.1029/2000JA000365, 2001

Richards, P.G., D. Bilitza, and D. Voglozin, Ion density calculator (IDC): A new efficient model of ionospheric ion densities, Radio Sci., 45, RS5007, DOI: 10.1029/2009RS004332, 2010.

Scherliess, L., D.C. Thompson, and R.W. Schunk, Longitudinal variability of low-latitude total electron content: Tidal influences, J. Geophys. Res., 113, A01311, DOI:10.1029/2007JA012480, 2008.

Schmidt, M., D. Bilitza, C.K. Shum, and C. Zeilhofer, Regional 4-D modeling of the ionospheric electron density, Adv. Space Res., 42 (4), 782-790, DOI: 10.1016/j.asr.2007.02.050, 2008.

Shim, J.S., M. Kuznetsova, L. Rastätter, M. Hesse, D. Bilitza, et al, CEDAR Electrodynamics Thermosphere Ionosphere 1 (ETI) challenge for systematic assessment of ionosphere/thermosphere Models 1: $\mathrm{NmF} 2, \mathrm{hmF} 2$, and vertical drift using ground based observations, Space Weather, 9, S12003, DOI:10.1029/2011SW000727, 2011.

Shim, J.S., M. Kuznetsova, L. Rastätter, M. Hesse, D. Bilitza, et al., CEDAR Electrodynamics Thermosphere Ionosphere (ETI) Challenge for systematic assessment of ionosphere/thermosphere models: Electron density, neutral density, $\mathrm{NmF} 2$, and hmF2 using space based observations, Space Weather, 10, S10004, DOI: 10.1029/2012SW000851, 2012.

Sethi, N.K., R.S. Dabas, P. Bhawre, and S.K. Sarkar, Bottomside profile shape parameters during low solar activity and comparison with IRI-2007 model, J. Atmos. Sol. Terr. Phys., 71, 1935-1942, DOI:10.1016/j.jastp.2009.08.003, 2009.

Spenner, K., and R. Plugge, Empirical model of global electron temperature distribution between 300 and $700 \mathrm{~km}$ based on data from AEROS-A, J. Geophys., 46, 43-56, 1979.

Spiro, R.W., P.H. Reiff, and L.J. Maher, Jr., Precipitating electron energy flux and auroral zone conductances - an empirical model, J. Geophys. Res., 87, 8215-8227, 1982.
Strickland, D.J., J. Bishop, J.S. Evans, T. Majeed, P.M. Shen, R.J. Cox, R. Link, and R.E. Huffman, Atmospheric ultraviolet radiance integrated code (AURIC): theory, software architecture, inputs, and selected results, J. Quant. Spectrosc. Radiat. Transfer, 62, 689, 1999

Szuszczewicz, E.P., P. Wilkinson, W. Swider, S. Pulinets, M.A. Abdu, et al., Measurements and empirical model comparisons of F-region characteristics and auroral boundaries during the solstitial SUNDIAL campaign of 1987, Ann. Geophys., 11, 601-613, 1993.

Triskova, L., V. Truhlik, and J. Smilauer, An empirical model of ion composition in the outer ionosphere, Adv. Space Res., 31 (3), 653-663, DOI: 10.1016/S0273-1177(03)00040-1, 2003.

Truhlik, V., L. Triskova, J. Smilauer, and V. Afonin, Global empirical models of electron temperatures in the outer ionosphere for period of high solar activity based on data of three Intercosmos satellites, Adv. Space Res., 25 (1), 163-172, 2000.

Truhlik, V., L. Triskova, and J. Smilauer, New advances in empirical modeling of ion composition in the outer ionosphere, $A d v$. Space Res., 33 (6), 844-849, DOI: 10.1016/j.asr.2003.06.006, 2004.

Truhlik, V., D. Bilitza, and L. Triskova, Latitudinal variation of the topside electron temperature at different levels of solar activity, Adv. Space Res., 44 (6), 693-700,

DOI: $10.1016 /$ j.asr.2009.04.029, 2009.

Truhlik, V., D. Bilitza, and L. Triskova, A new global empirical model of the electron temperature with inclusion of the solar activity variations for IRI, Earth Planets and Space, 64 (6), 531-543, 2012.

Wallis, D.D., and E.E. Budzinski, Empirical models of height integrated conductivities, J. Geophys. Res., 86, 125-137, 1981.

Yue, X., W.S. Schreiner, Y.-H. Kuo, D.C. Hunt, W. Wang, et al., Global 3-D ionospheric electron density reanalysis based on multi-source data assimilation, J. Geophys. Res., 117, A09325, DOI: 10.1029/2012JA017968, 2012.

Zhang, M.-L., W. Wan, L. Liu, and J.K. Shi, Variability of the behavior of the bottomside (B0, B1) parameters obtained from the ground-based ionograms at China's low latitude station, $A d v$. Space Res., 42 (2), 695-702, DOI: 10.1016/j.asr.2007.07.022, 2008.

Zhang, S.-R., J.M. Holt, A.P. van Eyken, M. McCready, C. AmoryMazaudier, S. Fukao, and M. Sulzer, Ionospheric local model and climatology from long-term databases of multiple incoherent scatter radars, Geophys. Res. Lett., 32, L20102, DOI: 10.1029/2005GL023603, 2005.

Zhang, Y., and L.J. Paxton, An empirical Kp-dependent global auroral model based on TIMED/GUVI data, J. Atmos. Sol. Terr. Phys., 70, 1231-1242, DOI: 10.1016/j.jastp.2008.03.008, 2008.

Zhang, Y., L.J. Paxton, and D. Bilitza, Near real-time assimilation of auroral peak E-region density and equatorward boundary in IRI, Adv. Space Res., 46 (8), 1055-1063, DOI: $10.1016 /$ j.asr.2010.06.029, 2010.

Cite this article as: Bilitza D, Altadill D, Zhang Y, Mertens C, Truhlik V, et al.: The International Reference Ionosphere $2012-\mathrm{a}$ model of international collaboration. J. Space Weather Space Clim., 2014, 4, A07. 